\title{
Spatio-Temporal Dynamics of Urban Expansion of Cochin City Region in GIS based on Buffer Gradient Analysis
}

\author{
Jayalakshmy S. S. ${ }^{1}$, Mereena C. S. ${ }^{2}$ \\ ${ }^{1,2}$ National Centre for Earth Science Studies, Akkulam, Thiruvananthapuram, Kerala, 695011, India,
}

\begin{abstract}
A comprehensive assessment and proper methodology is inevitable for urban planning. This study is to identify spatiotemporal trends of urban expansion and intensity in Cochin city region and its satellite towns. To measure the magnitude and pace of urban growth and Urban proportional Index (UPI) and Urban Intensity Index (UII) were developed. GIS based buffer analysis was adopted in this study. Two distinct phases of urbanization are discernible i.e. phase of rapid urbanization (1990-2000)and Phase of diffusive urbanization(2000-2010).The Cochin urbanization is characterised by a transformation from being localized, high intensity and uniform to diffusive regionalized and complementary.
\end{abstract}

Keywords: Urban proportional Index, Urban Intensity Index, Satellite town.

\section{Introduction}

Urbanisation in a demographic sense is defined as a process of growing population concentration whereby the proportion of the total population which is classified as urban is increasing. As far as urban growth is concerned there are three components; natural increase, net in-migration and changes in city boundaries which result in incorporation of previously rural places (Lipton, 1977; Pacione, 2009). Urban areas are characterized by a central feature: they concentrate population, energy and materials, industrial and commercial activities, and buildings and infrastructure. It is not any single one of these factors, but the confluence of them that defines urban area. Indeed, although there is no uniform or globally consistent definition of "urban", most countries define urban according to a criteria pertaining to some aspect of a region's population, economy, or built infrastructure (UN, 2007) .The only consistent thing about cities is that they are always changing cities since their inception have always demonstrated gradual, piecemeal change through processes of accretion, addition or demolition. This type of change can be regarded as largely cosmetic and the underlying processes of urbanisation and the overall structure of the city remained largely unchanged (Hall, 1998). To understand the mechanism of urbanisation of a particular region, it is necessary to understand the growth of its satellite towns and the trend of its urbanisation and its role in the growth of regional economy and how they contribute to development of city centre. (Xiaowen Li, 2010)

The basic premise in using remote sensing data for change detection is that the process can identify change between two or more dates that is uncharacteristic of normal variation.(Muc-honey and Haack, 1994; Singh, 1989; Shalaby and Tateishi,2007).Remote sensing allows retrospective viewing of earth's surface, and time- series of remote sensor data can be used to develop a historical perspective of an urban attribute or process which can help examine significant human or natural processes that act over a long time period.(Xiaojun,2011).
Urbanization in India is as pseudo urbanization were in people arrive to cities not due to urban pull but due to rural push(Breese 1969).Traditionally, India's urbanization pattern is an illustration of highly polarised and spatially unbalanced urban system with sharp core-periphery differences. However, recent trends show that urban industrial interaction fields are spreading through linking rural areas and also small towns around the mega cities and urban corridors are emerging along the transport routes (Chattopadhyay S., 2007).

Kerala shows a distinctive pattern of rural-urban continuum throughout the state where it is difficult to demarcate urban and rural area, it presents a different picture in the matter of urbanisation from the rest of India due to dispersed nature of settlements, growth of tertiary sector and unique rural-urban continuum manifested throughout the state. Ernakulum is the most urbanised district in the state in terms of absolute number of urban population (2234363 population as per 2011 census). Cochin city region encompasses most of urban centres in the Ernakulum district; economically active region in the state.

The present study addresses urbanisation in both spatial and temporal contexts and explores urban expansion of the Cochin city and satellite towns as well as their interaction in the regional urbanisation. Three sets of LANDSAT images were used and GIS based buffer system was established covering the central and major satellite towns of Cochin.

\section{Objectives}

- To identify spatiotemporal trends of urban expansion and urbanisation intensity across the Cochin city region.

- To understand spatiotemporal characteristics of urban expansion of major satellite towns and the core-periphery relationship with the urban centre 


\section{International Journal of Science and Research (IJSR) \\ ISSN (Online): 2319-7064}

Index Copernicus Value (2013): 6.14 | Impact Factor (2015): 6.391

\section{Study Area}

Cochin is one of the largest and most important commercial and industrial centres of Kerala. Its strategic importance over the centuries is underlined by the Arabian Sea. Cochin city region is situated on the south-west coast of Indian peninsula with an administrative area of 369.72 sq. km which fall within the geographical co-ordinates $9047^{\prime} 14^{\prime} \mathrm{N}$ to $1005^{\prime} 38^{\prime \prime} \mathrm{N}$ and 760 12'22"E to $76025^{\prime} 50$ 'E. The Cochin Corporation, five municipalities and nine panchayats fall in the present Cochin City Region. It is located on the south-western coastal strip of India. Cochin is inseparably linked with the wetlands of Vembanad estuary. Cochin, is a region interspersed with tidal water bodies and all developmental initiatives have to be streamlined giving due respect to the geological and ecological fingerprints of the region. Large scale projects especially in construction sector, Information Technology, transport, existence of Vallarpadam container shipment contributed to the urbanisation of Cochin city.

The study area covers the Cochin city region. This is because the present study focuses on the urban expansion in Cochin city region; therefore it should focus on Cochin city and include major satellite towns.

\section{LOCATION MAP}

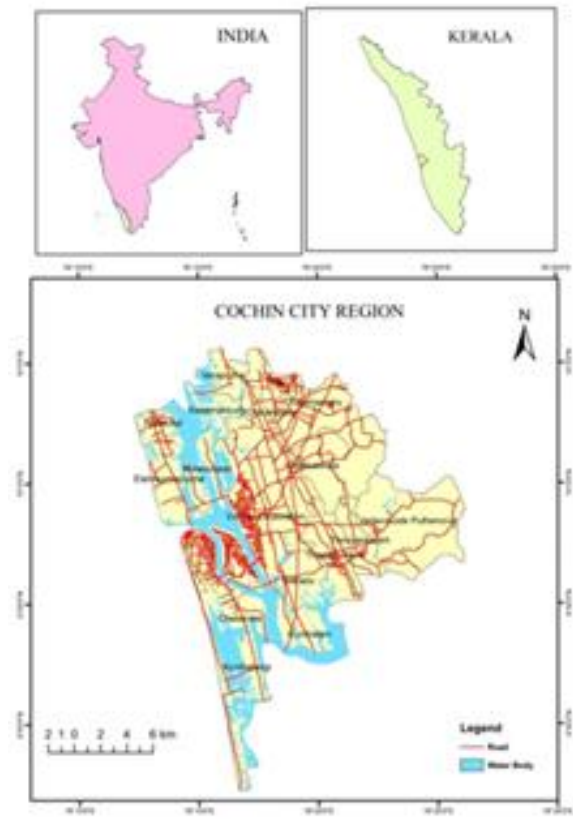

Figure 1: Location map of Cochin city region

\section{Methodology}

Two sets of LANDSAT TM images (1990/2000, resolution $30 \mathrm{~m}$, seven bands) and one LANDSAT ETM+ (2010, resolution $15 \mathrm{~m}$, seven band) were used in the study. These images were processed with ERDAS IMAGINE software, which involves geometric correction, unsupervised classification and GIS reclassification. The different bands of imageries were stacked to produce a False Colour Composite (FCC). The Panchromatic data were merged with multispectral FCC. The base map (Cochin City Region Development Plan, 2031) of the study area was imported in computer environment and georeferenced in GIS environment. By using this shape files were generated. The sub-setting of satellite images were performed for extracting study area by taking geo-referenced outline Cochin City Region Development Plan boundary of 2031 map. The subset image was then re-projected. All three images were then classified using ISODATA unsupervised classification algorithm. Thirty spectral clusters with 95\% convergence value were selected to perform unsupervised classification. Through visual examination of satellite imageries, and by using toposheets and Google earth images, digitally classified images were interpreted and reclassified. Through the use of spectral classification, the urban area was extracted, which include high density residential areas and newly developed zone.

To measure and quantify the magnitude and pace of urban growth and Urbanisation Proportional Index (UPI) and Urbanisation Intensity Index were developed and employed (Liu, 2000) which expressed as

UPIi, $\mathrm{t} \sim \mathrm{t}+\mathrm{n}=($ ULAi, $\mathrm{t}+\mathrm{n}-$ ULAi,t) $* 100 /$ TLAi

UIIi, $\mathrm{t}+\mathrm{t}+\mathrm{n}=[(\mathrm{ULAi}, \mathrm{t}+\mathrm{n}-\mathrm{ULAi}, \mathrm{t}) / \mathrm{n}] * 100 / \mathrm{TLAi}$

The variables UPIi, $\mathrm{t} \sim \mathrm{t}+\mathrm{n}, \mathrm{UIIi}, \mathrm{t} \sim \mathrm{t}+\mathrm{n}, \quad$ ULAi, $\mathrm{t}+\mathrm{n} \quad$ and ULAi,tare indices of the proportion of urbanization and the intensity of urbanization within a spatial unit i during a time period $t \sim t+n$, and the areas of urban land-use for years $t+n$ and $t$, respectively. TLAi is the total area of the spatial unit $i$. The UPI expresses the percentage of the total area occupied by urban expansion for a given spatial unit over the entire course of the study from 1990 to 2010, and it reveals the total magnitude and spatial distribution patterns of urban expansion throughout this period. The UII is used to compare the pace and intensity of urban expansion over various periods.GIS-based buffer analysis was adopted in this study. ArcGIS software was used for buffer analysis. Each buffer zone was employed as a basic spatial unit to characterize distance-dependent urban growth behaviour with their UPI and UII values for a given time period. For the purpose of the study, three different buffer systems were established. The first was a circular buffer zone system with a buffer width of $2 \mathrm{~km}$ covering the entire region. This was designed to explore the overall urbanisation process over the city region comprising the Cochin city and its suburbs. The second buffer system was established by creating separate buffer zones around Cochin city centre and its five major satellite towns. In this analysis, the buffer zones covering the Cochin city centre and satellite towns were defined as having a $0.5 \mathrm{~km}$ width which was enough to include the principal urban centre of Cochin and urban areas of each satellite city.

In all buffer analysis urban areas of Cochin city region indicated by LANDSAT data from 1990, 2000 and 2010 were extracted and used to represent the urban centre as a baseline for creating buffer zones. Because the urban centre of each satellite city was generally not obvious, the CBD of each satellite city during the first time phase (1990) was used as the origin in creating the buffer zones. 


\section{Results and Analysis}

\subsection{Spatiotemporal trends of UII based on buffer analysis} during 1990-2010.

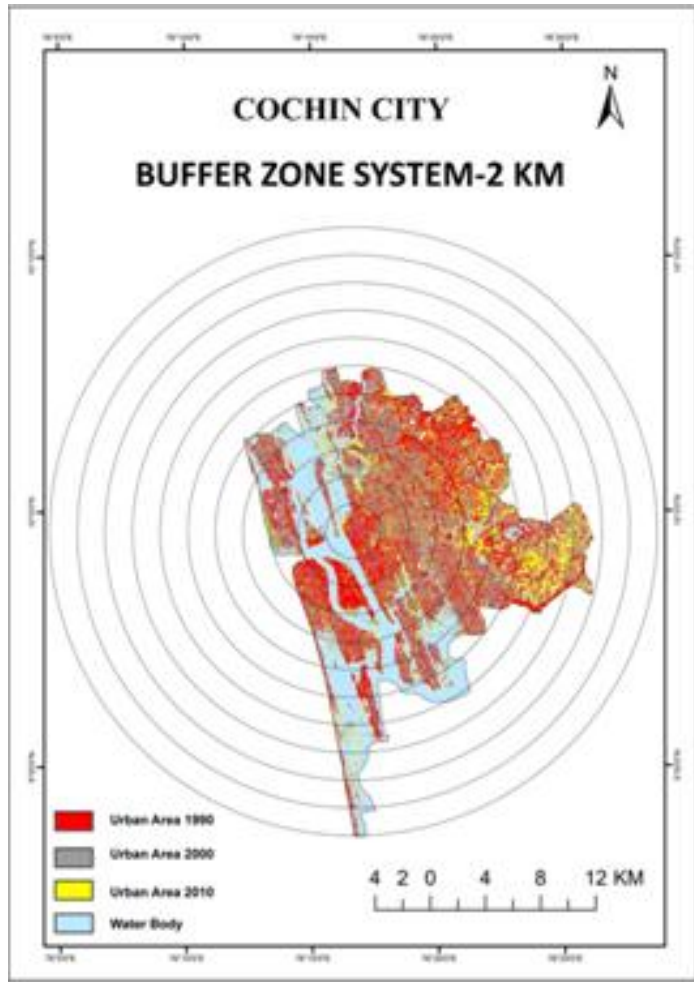

Figure 2: Buffer system surrounding Cochin city

\section{Cochin City Region : 1990-2010}

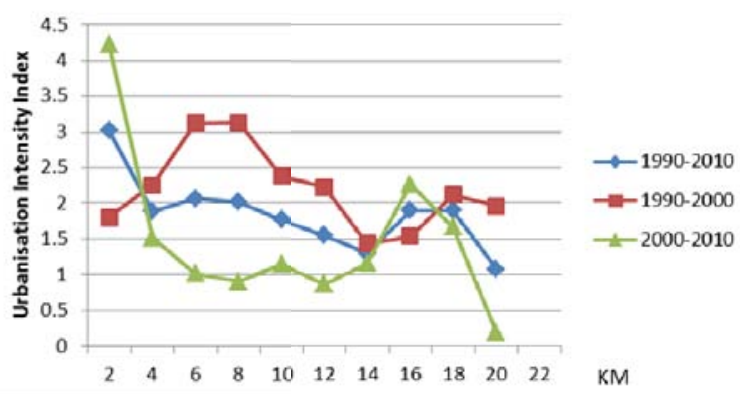

Figure 3: Changes in UII with distance from Urban centre over the Cochin cityregion from 1990-2010

Figure 2 displays the expansion of urban area for the entire Cochin city region over each time interval. Figure 3 displays the UII resulting from buffer zone analysis for the entire Cochin region over each time interval. During 1990-2000 buffer zone within $2 \mathrm{~km}$ shows a gradual upward increase in UII. This is the core of the city and it is well developed from very earlier days and has developed as CBD. Wellconnected transportation network added more advantage to the urbanization of this region. Between 2-4 km it shows a slight increase. This is because this zone which includes Mattancherry is well developed from the historical times itself. The earlier settlements of Cochin were developed at Mattancherry. The zone had developed as a typical orient market town, with commercial activities distributed along the waterfronts. Mattancherry grew into a market town with cosmopolitan character attracting foreign traders. UII shows a sharp increase between 4 to $6 \mathrm{~km}$. Port based developments in Elamkunnappuzha accelerated the urban growth. Edapally, Vytilla and Kudannur along NH 47 developed as active note of the city. The UII curve between $6-8 \mathrm{~km}$ shows a uniform trend of increase having a peak value. The zone includes major towns like Maradu, Thripunithura, Thrikkakara, Kakkanad, Fort Cochin and Thoppinpadi. Thripunithura has developed as commercial centre of importance. The NW3 being developed from the northern side of Cochin city, causing marginal growth in the surrounding area. Apartment housing is a major trend in Maradu and Thrikkakara. The urban expansion is less in between $8-12 \mathrm{~km}$ compared to other zones. Although the UII rate is less, the zone is a hub of large scale industries which prevent further urban expansion. The urban intensification is high between $12 \mathrm{~km}$ to $18 \mathrm{~km}$. This zone has developed due to its geographical location and the physical development activities implemented by the government. Fishing and tourism provide economic base for the economic development of this region. The UII between $18-22 \mathrm{~km}$ shows a gradual decline as the land area is limited.

In 2000-2010 the UII is at its peak in and around $0-2 \mathrm{~km}$ of the city region. It shows a high intensification of urbanization within $2 \mathrm{~km}$ of city region. In between $4-8 \mathrm{~km}$ it shows a steady declining trend from the city centre because the zone is already well developed and the vacant space for expansion is negligible. Again the UII shows a gradual rise than the previous buffer zone between $8-10 \mathrm{~km}$ because the zone is concentrated with diversified economic activities such as IT parks and related developments, banking and other financial institutions, Cochin Stock Exchange and tourism. The next zone between $10-12 \mathrm{~km}$ shows a gradual decline. The zone between $12-16 \mathrm{~km}$ shows a steady growth due to major investments like Smart city, Brahmapuram Power Plant. There is a huge potential for development of heavy industries and land intensive developments in this area. The buffer zone between 16-22 km shows a sharp decline as the zone is mixed with rural economic activities and also the land area is limited.

\subsection{Spatiotemporal characteristics of UII for the major satellite towns}

Figure 5 and Figure 6 shows the trends in the UII with distance from each satellite town centre. During each time period, each town's UII curve has a distinct association with the overall trend of downtown Cochin city, yet the strength of this association and the intensity variations for various time periods have clear individual differences. This shows that on the one hand, the urbanization of these satellite towns cannot avoid being influenced and shaped by Cochin's urbanization, yet on the other hand, they also have their own relatively independent expansion processes. The interaction between the "passive" and "active" aspects of urbanization results in the diversity and complexity of suburban or rural urbanization. (Li, 2010). 


\section{International Journal of Science and Research (IJSR) \\ ISSN (Online): 2319-7064}

Index Copernicus Value (2013): 6.14 | Impact Factor (2015): 6.391

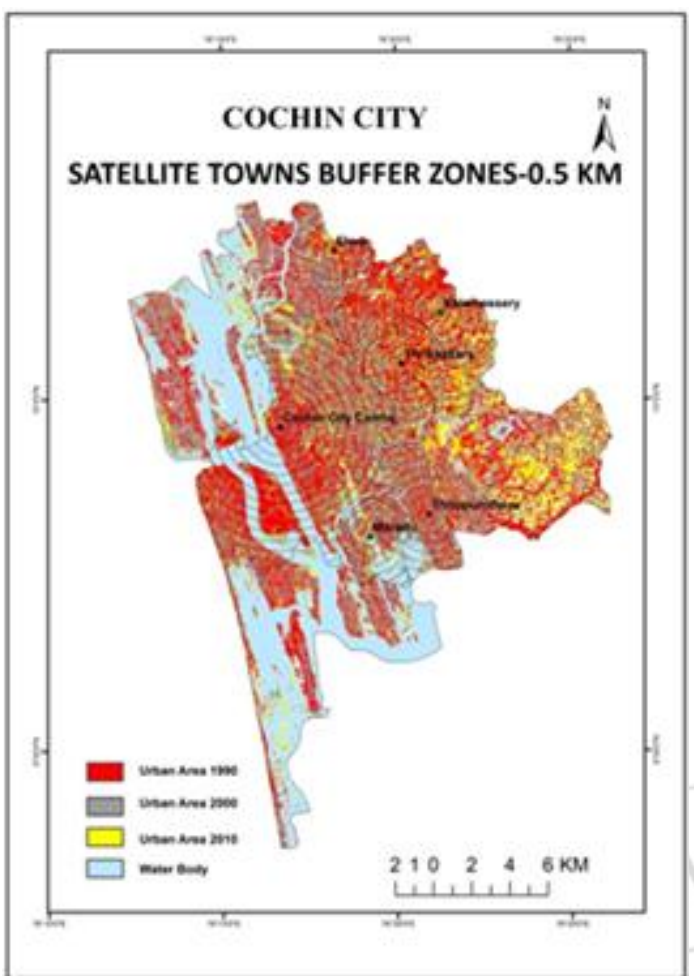

Figure 5: Complex buffer zone system established by delineating separate buffer zones around the Cochin city and its five satellite towns to compare spatiotemporal characteristics of urban expansion between the Cochin city and its major satellite towns. The width of the buffer zones covering the Cochincityand satellite towns were defined as $0.5 \mathrm{~km}$ in width.

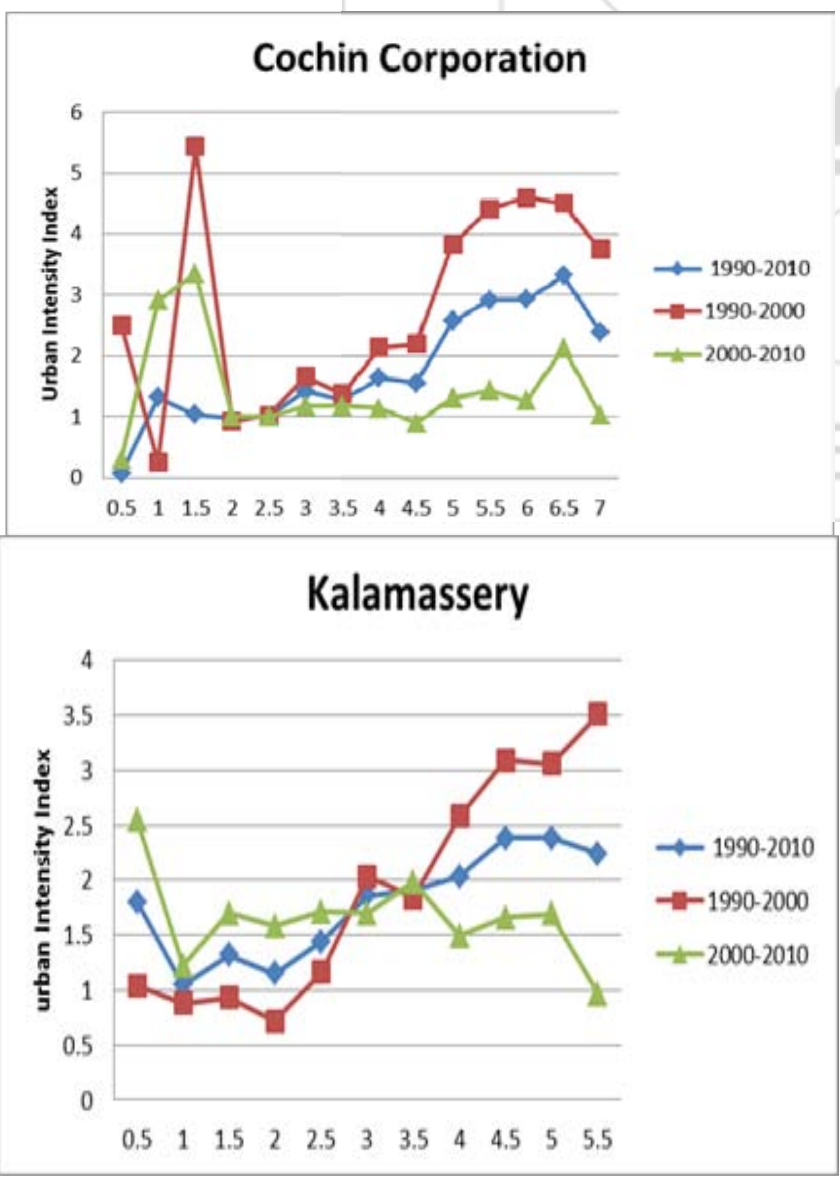

Eloor

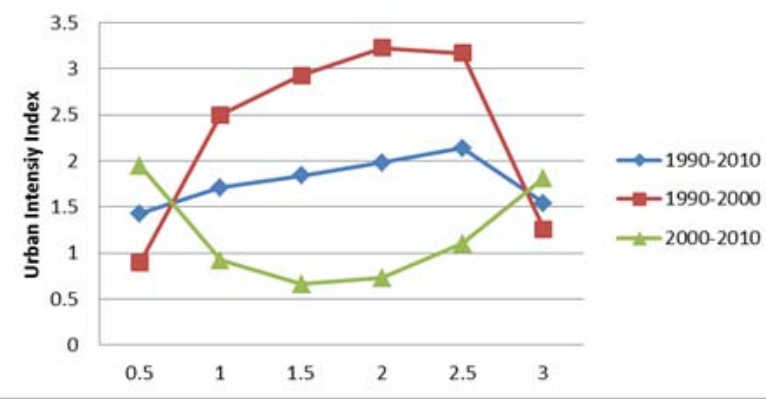

Maradu

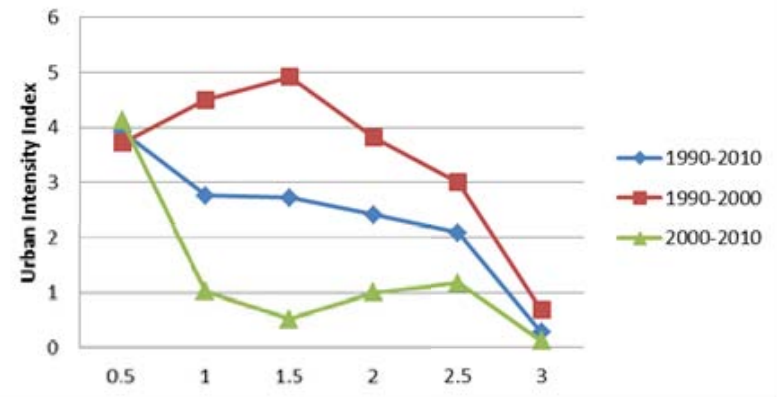

Thrippunithura

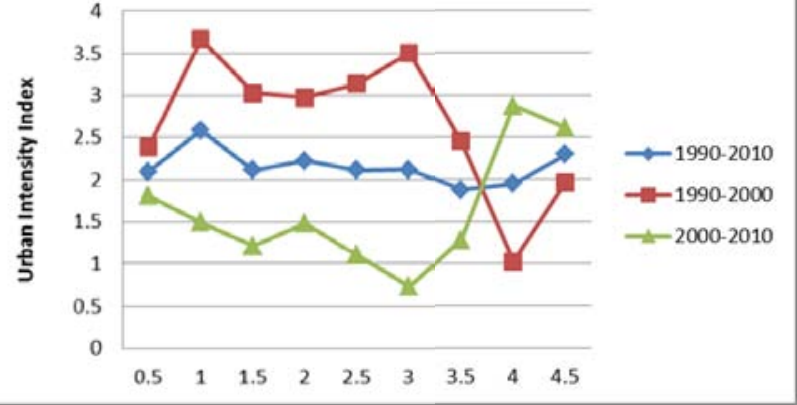

Thrikkakara

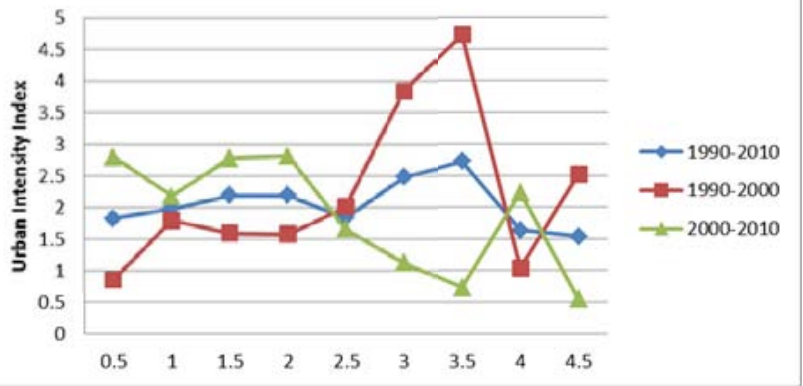

Figure 6: Comparing the trends of the UII with distance to the urban centre among the five major satellite cities in the Cochin city region during different time periods from 1990 to 2010

5.3Spatiotemporal characteristics of UPI for the major satellite towns 


\section{Urban Proportional Index 1990-2000}

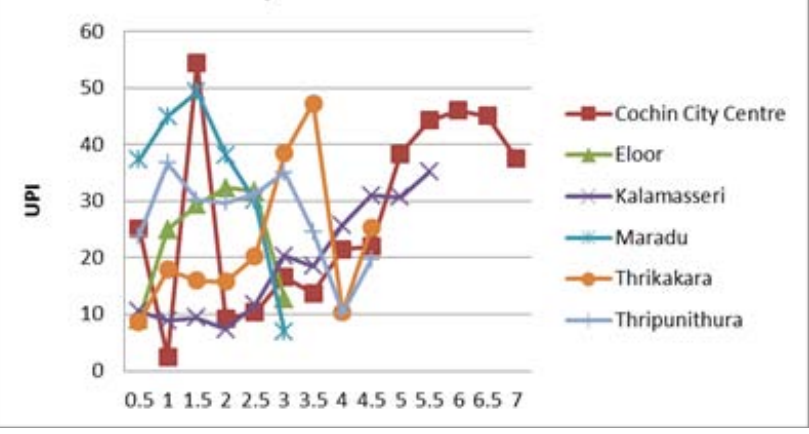

\section{Urban Proportional Index 2000-2010}

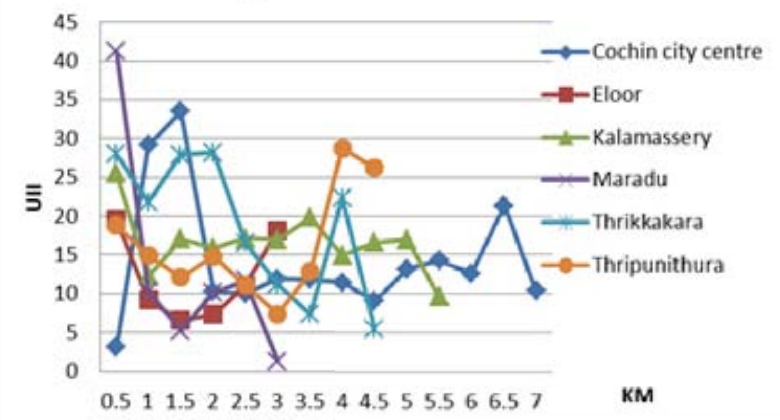

Figure 7: Comparing trends of Urbanisation Proportional Index(UPI) between Cochin city centre and its major satellite towns with the distance to the urban centres over 1990-2010, the five major satellite towns are Eloor, Kalamassery, Maradu, Thrikkakara and Thripunnithura

While analysing the Figure 7 it is evident that Cochin city's urban intensity and magnitude of urbanization much higher than its satellite towns. Urban proportional index of Cochin city shows that in 1990-2000 its urbanization intensity is more fluctuating in nature especially in the initial periods. It touches it peak at $1.5 \mathrm{~km}$ from the city centre and recorded more than $50 \%$ of urbanization and then it decreased between 2 to $3.5 \mathrm{~km}$.After $4.5 \mathrm{~km}$ it retains its pace up to $6.5 \mathrm{~km}$ then it shows a declining trend. Maradu and Thripunithura have already achieved a high UPI in 19902000. In its initial change both the regions have its best urban intensity on the $1.5 \mathrm{~km}$ i.e. $49 \%$ and $36.74 \%$ respectively. Except Eloor and Maradu all the other satellite towns shows decreasing trend between 1.5 to $2.5 \mathrm{~km}$. Thrikkakara and Thripunithura have its high intensity of urbanization around 3 to $5.5 \mathrm{~km}$ demonstrating more robust expansion maintained within this region .But in the case of Maradu and Eloor the UPI dramatically declines after $2.5 \mathrm{~km}$.Passive mode of urbanization is in the periphery of Cochin city with the satellite towns of Thrikkakara and Maradu regions which is mutually intensifying and reinforcing the two suburbs. Kalamassery is the only satellite town which shows a positive urban expansion where it UPI shows a gradual increase from the city core in its outward stretch where it records a high UPI.

During 2000-2010 in the initial phase all satellite towns UPI is high around $1.5 \mathrm{~km}$ from centre .In the downward margins all satellite towns shows a dramatically declining trend where it shows the reduction of intensity far from city core.
Except Kalamassery all other have low UPI in its innermost areas, hence the merging and intensification of urbanization of Kalamassery satellite town took place in the outskirt reaches around $3 \mathrm{~km}$ from city centre

\subsection{Findings}

With economic development and population growth, the process of Urbanization of Cochin city had accelerated and the area of urban land increased quickly.

\section{Two distinct phases of urbanisation are discernible}

\section{a) Phase of Rapid Urbanisation (1990-2000)}

This phase is characterised by large scale urban expansion and the urbanisation intensity increases as a whole. There is a rapid expansion in the urban expansion zone. This is because the city centre, Mattancherry, Fort Cochin, Ernakulum regions immediately surrounding the city centre has already developed and urbanised and the areas surrounding it like Maradu, Edapally, Eloor , Kalamassery, Thrikkakara, Thripunithura partly transformed into new urban centres, the urban expansion zone rapidly moves outward with a drastic increase in area. On the outer side of urban expansion zone the urban expansion intensity decreases.

\section{b) Phase of diffusive urbanisation (2000-2010)}

Urban expansion has already caused considerable growth of urban area, as well as outward expansion of the urbansuburban transition zone. The extent of urban expansion zone also continues to increase and the top values of UII are at points further from the original urban centres but with lower values. The urbanization is characterized by a transformation from being localized, high intensity and uniform to diffusive, regionalised and complementary. Therefore UII peak values are lower than those in earlier phase.

\section{Conclusion}

The Spatio temporal analysis of urban expansion reveals the intensity of urbanization of a particular area and how it influencing landscape of region. Through the analysis it reveals that the urban expansion is the product of socio economic and demographic factors individually and sometimes with its association. In the Case of Cochin the economic demographic\& social parameters are go hand in hand. It record a rapid urbanization during 1990-2000 period.Among the satellite towns, the urban expansion was observed active for Maradu, Kalamassery and Thripunithura. Residential apartments in Maradu, IT parks at Kalamassery, Heritage tourism and residential buildings in Thripunithura accelerated the urban growth. The developmental activities such as Cochin metro rail, Port related activities in Wellington Island, Elamkunnappuzha, Mulavukadu, Njaraikkal, Kadamankkudy, Heritage and tourism activities in Fort Cochin and Mattancherry, Fishing and tourism in Chellanam and Kumbalangy, industrial activities in Vadavucodu- Puthenkurisu, Kalamassery and Thrikkakara, Residential activities in Maradu, Kumbalam, Thripunithura 


\section{International Journal of Science and Research (IJSR) \\ ISSN (Online): 2319-7064 \\ Index Copernicus Value (2013): 6.14 | Impact Factor (2015): 6.391}

and Thiruvankulam accelerates future trend of urban expansion.

\section{Acknowledgement}

The authors greatly indebted to Dr. Srikumar Chattopadhyay, Rted Scientist, National Centre for Earth Science Studies for his valuable and critical comments that enhanced the capability of this research paper. We thank the hosting institution NCESS for providing necessary facilities to carry out this work. The financial support from UGC and DST is thankfully acknowledged.

\section{References}

[1] Asian Development Bank (2014). Sustainable Urbanization in Asia and Latin America.Phillipines

[2] Belal A.A.,F.S. Moghanm. (2011).Detecting urban growth using remote sensing and GIStechniques in $\mathrm{Al}$ Gharbiya governorate, Egypt. The Egyptian Journal of Remote Sensing and Space Sciences, 73-79

[3] Cui Linli and Jun Shi(2012), Urbanization and its environmental effects in Shanghai, China, Elsevier, Urban Climate, 1-15

[4] Development Plan for Kochi City Region 2031(2010). Department of Town and Country Planning (Draft), Vol 1

[5] Dhanuraj D, Madhu S, Yogi Joseph(2012).A Study Of Inland Water Transportation in Kochi City region, Centre for Public Policy Research, Working paper series.

[6] Ismail Wan Hashimah Wan (2011), Sustainable Urbanisation on the Western Side of the historic City of Malacca, Elsevier, Procedia Social and Behavioural Science, 632-639

[7] Kundu Sridhar and Sanchita Deb Roy (2012) Urbanisation and de-sanitation: A de-compositional analysis by taking a case study of few Indian cities, Elsevier, Procedia Social and Behavioural Science, 427 $-436$.

[8] Li Xiaowen, Lina Zhang, Chen Liang (2010). A GISbased buffer gradient analysis on spatiotemporal dynamics of urban expansion in Shanghai and its major satellite cities. Procedia Environmental Sciences 2 (2010), 1139-1156.

[9] Mikovits C, W. Raucha and M. Kleidorfer (2014), Dynamics in urban development, population growth and their influences on urban water infrastructure, Elsevier, Procedia Engineering, 1147- 1156

[10] Mohan Manju and Anurag Kandya (2015). Impact of urbanization and land-use/land-cover change on diurnal temperature range: A case study of tropical urban airshed of India usingremote sensing data, Elsevier, Science of the Total Environment, 453-465.

[11]Narain Vishal (2009), Shrinking hinterland: Land acquisition transition and conflict in peri-urban Gurgaon, India, Environment and Urbanisation, Vol 21, 501-511.

[12] Oana Petrov Laura, Shahumyan Harutyuna, Williams Brendana and ConverySheila (2011), Scenarios and Indicators Supporting Urban Regional Planning, Elsevier, Procedia Social and Behavioural Sciences, 243-252.
[13] Oindrila DattaGupta (2014).Global Integration and Developing Indian "Smart Cities": New Hopes and Challenges. International journal of Innovative Social Science Humanities Research, Vol (1), Issue-2, 30-42

[14]Pons Antoni and Onofre Rullan (2014).The expansion of urbanisation in the BalearicIslands (19562006).Journal of Marine and Island Cultures.

[15] Price Bronwyn, Felix Kienast, Irmi Seidl, Christian Ginzler, Peter H. Verburg and Janine Bolliger (2015). Future landscapes of Switzerland: Risk areas for urbanisation and land abandonment, Elsevier, Applied Geography, 57, 32-41

[16]R.Suja, J.Letha and Jiji Varghese (2013).Evaluation of Urban growth and expansion using Remote sensing and GIS. International Journal of Engineering Research \& Technology (IJERT), Vol. 2 Issue 10, 2772-2779.

[17] RamachandraT.V, A.H. Bharath and M.V. Sowmyashree (2015).Monitoring urbanization and its implications in a mega city from space: Spatiotemporal patterns and its indicators. Journal of Environmental Management (Elsevier), 148, 67-81

[18] Salleh Siti Aekbal, Zulkiflee Abd.Latif, Wan Mohd. Naim Wan Mohda and Andy Chan (2013).Factors Contributing to the Formation of an Urban Heat Island in Putrajaya, Malaysia, Elsevier, Social and Behavioral Science, 840-850

[19] Sha Moquan and Guangjin Tian (2010). An analysis of spatiotemporal changes of urban landscape pattern in Phoenix metropolitan region, Elsevier, Procedia Environmental Sciences, 600-604

[20] Thakur Baleshwar, George Pomeroy, Chris Cusack and Sudhir K Thakur (2007).City Society and Planning. Concept Publishing Company, New Delhi

[21] Thomas George, Sherin A.P, Shareekul Ansar and E.J. Zachariah (2014), Analysis of urban heat island in Kochi, India, using a modified local climate zone classification, Elsevier, Procedia Environmental Sciences, 3-13

[22] Tian Hanqin, Kamaljit Banger, Tao Bo and Vinay K. Dadhwal (2014), History of land use in India during 1880-2010: Large-scale land transformations reconstructed from satellite data and historical archives, Elsevier, Global and Planetary Change, 78-88.

[23] Vij Dimpal (2012), Urbanization and solid waste management in India: Present practices and future challenges, Elsevier, Social and Behavioral Science, 437-447

[24]Wu Shaohua, Shenglu Zhou, Dongxiang Chen, Zongqiang Wei, Liang Dai and Xingong Li (2014).Determining the contributions of urbanisation and climate change to NPPvariations over the last decade in the Yangtze River Delta, China, Elsevier, Science of the Total Environment, 472, 397-406.

[25] Yang Xiaojun (2011). Urban Remote Sensing Monitoring, Synthesis and Modeling in the Urban Environment, Wiley- Blackwell, Oxford U.K.

[26] Zhan S.F., X.C. Zhang C. M and W.P. Chen (2012), Dynamic modelling for ecological and economic sustainability in a rapid urbanizing region, Elsevier, Procedia Environmental Sciences, 242-251

[27]ZhangQingling and Karen C. Seto(2011).Mapping urbanization dynamics at regional and global scales using multi-temporalDMSP/OLS nighttime light data, 


\section{International Journal of Science and Research (IJSR) \\ ISSN (Online): 2319-7064}

Index Copernicus Value (2013): 6.14 | Impact Factor (2015): 6.391

Elsevier, Remote Sensing of Environment, 115, 23202329.

[28] Zhongping Wang, Shi Changliang, Li Qiang and Wang Gang (2011), Coupling Trending Analysis about Urbanization and Urban Resource in Beijing, Elsevier, Energy Procedia, 1589-1596

[29] ZhouDi,Ping Shi, Xiaoqing Wu, Jinwei Ma and Junbao Yu(2014).Effects of Urbanization Expansion on LandscapePattern and Region Ecological Risk in Chinese Coastal City:A Case Study of Yantai City,Hindawi,1-9.

\section{Author Profile}

Jayalakshmy S.S. received the B.Sc. and Msc degrees in Geography from University of Kerala in 2007 and 2009 respectively. During 2009-2010 she pursued the Bachelor of Education degree in Geography. She is now doing PhD in National Centre for Earth Science Studies as UGC JRF. Her subject of interest is Urban Geography.

Mereena C.S.received the BSc degree in Geography from University of Kerala in 2010 and Msc degree in Geography from Kannur University in 2012. She pursued the Bachelor of Education degree in Geography during 2012-2013. She is now doing research in the field of Transport Geography in National Centre for Earth Science studies as DST INSPIRE Fellow. 